\title{
Trait distinctiveness and age specificity in self-referent information processing
}

\author{
JOHN H. MUELLER and W. CALVIN JOHNSON \\ University of Missouri, Columbia, Missouri
}

\begin{abstract}
College students and elderly adults made both self-descriptiveness and other-descriptiveness decisions for the same set of 80 trait adjectives. Half of the adjectives were appropriate descriptors of young adults rather than elderly adults, whereas the remainder were more appropriate as descriptors for elderly adults. Rating each trait twice made it possible to separate the items that were descriptive of both self and others (shared) from those that were descriptive of self only (unshared). Adjective endorsement by young adults showed age specificity for the shared (both) traits, particularly for the likable adjectives, but not for the unique (self-only) traits. The endorsement pattern of elderly adults showed no age specificity for either shared or unshared traits, though the elderly adults did access elderly items faster than young items.
\end{abstract}

A number of recent experiments have indicated that certain orienting activities help integrate new experiences with preexisting cognitive structures. In particular, an orienting judgment that refers new material to information in the self concept seems especially useful (Rogers, Kuiper, \& Kirker, 1977). For example, deciding that an adjective describes oneself subsequently yields better retention of that adjective than would be the case for making a synonym judgment, and self-reference decisions are generally made more quickly than other decisions (see Greenwald \& Pratkanis, 1984).

One line of research has examined the generality of such self-reference benefits. For example, Derry and Kuiper (1981) argued that if the self concept is distorted so that certain information is missing, then self-referencing that type of material will be ineffective. This content-specificity hypothesis was supported when depressed subjects showed self-reference benefits only for depressed-content adjectives (e.g., bleak, gloomy) and showed no such benefits for nondepressed adjectives (e.g., energetic, amiable). Thus it appeared that self-reference benefits accrued specifically for content that was a part of the depressed subject's self concept (see also Markus, 1983).

This notion of content specificity can be extended to “age-specific" descriptors (Mueller, Wonderlich, \& Dugan, 1986), in that some adjectives are used to describe senior citizens more commonly than young adults (e.g., wise), and vice versa for other adjectives (e.g., robust). In addition, Heckhausen, Dixon, and Baltes (1989) have shown that subjects agree that certain behaviors should emerge or disappear at specific ages, reinforcing the notion of age specificity in the application of various descriptors. Age-appropriate behaviors and age-specific descriptors raise the prospect of age-related variation in the

Correspondence may be addressed to John H. Mueller, Psychology Department, 210 McAlester Hall, University of Missouri, Columbia, MO 65211 . contents of the self concept for young and elderly adults, thus suggesting possible limits on the benefits of selfreferencing for young and elderly adults. In other words, if depressed and nondepressed subjects show differences in self-referencing benefits traceable to presumed differences in the contents of their self concepts, can analogous limits be expected given age-related differences in the self concepts of young and old subjects?

Mueller et al. (1986) examined this question by having college students and elderly subjects make selfreference and other decisions for some trait adjectives that were normatively appropriate either for young adults or for elderly people. The results seemed to indicate that the self concept of young adults was more age-specific than was the case for the self concept of elderly subjects. That is, elderly adults seemed to possess both young and elderly traits in their self concept, perhaps as a residual of having been young once (see also Brewer \& Lui, 1984).

The purpose in the present experiment was to further examine age specificity, defined in terms of normative traits, and to integrate the normative approach with an idiographic definition of specificity. Some traits seem to be more general in that they are true of a number of people as well as oneself (i.e., they are shared), whereas other traits are more specific to oneself (they are unshared). Trait distinctiveness can be identified by requiring subjects to judge each adjective twice, once for selfdescriptiveness, and then again for other-descriptiveness (Mueller \& Ross, 1984; Mueller, Ross, \& Heesacker, 1984). Thus traits can be classified as (1) descriptive of both self and other, (2) descriptive of self but not othersself-only, (3) descriptive of others but not self-otheronly, or (4) descriptive of neither. In this way we can identify not only whether a trait is a part of the self concept, but also how central or distinctive the trait is for that individual.

In the present experiment, we used this idiographic strategy with trait adjectives that have been identified as 
normatively age-specific, and we sought to determine whether the self-only traits would show age specificity more clearly than the shared traits would. Of particular concern was whether the elderly would begin to show some age specificity if we examined just the most distinctive items, given that young adults have already shown age specificity more generally. Thus this procedure should clarify the locus (shared or unshared traits) of age-specific differences in terms of self content, and also should help determine whether the processing benefits accrue to just shared or unshared traits or both.

\section{METHOD}

\section{Subjects}

The young adults were 20 college students from introductory psychology courses, participating in return for extra credit in their course. Twenty elderly subjects were recruited from the community and paid $\$ 5.00$ for their participation. All were living at home and were in good general health at the time of the experiment. Various characteristics of the two groups are summarized in Table 1.

\section{Materials}

The 80 test items were selected following a preliminary screening phase involving the evaluation of over 170 words by both young and elderly adults. The details of this screening are available elsewhere (Mueller et al., 1986), but the primary criterion was that each trait seem to be more commonly used to describe people at one age level or the other. The 80 traits were grouped into four categories of 20 words each: elderly likable (e.g., composed, honorable, wise), elderly unlikable (e.g., forgetful, repetitive, tired), young likable (e.g., ambitious, hopeful, vigorous), and young unlikable (arrogant, immature, reckless).

\section{Procedure}

The rating phase involved self- and other-descriptiveness decisions for the 80 trait adjectives. The $\mathbf{8 0}$ items were randomly ordered for each subject, and presented one at a time on a video monitor controlled by a microcomputer, accompanied by one of two questions, "Describes you" or "Describes most people." The subjects responded "yes" or "no" by pressing a key on the keyboard. They were instructed to answer rapidly on the basis of first impression. They made a selfdescriptiveness judgment for all 80 words; then they saw the same 80 words in a different order and made a decision for each one about otherdescriptiveness. The order of the targets (self, other) was counterbalanced across subjects.

After the words had been rated twice, there was an unannounced free recall test. The subjects typed in as many of the $\mathbf{8 0}$ words as they could remember, or wrote them out for the experimenter to type in.

The next phase of the experiment was the Self-Consciousness Questionnaire (Buss, 1980). This instrument, which consists of 23 items answered on a 5-point scale, provides an estimate of private selfconsciousness (proneness to examine motives, moods, etc.), public selfconsciousness (monitoring of appearance to others), and social anxiety (arousal in the presence of others). Self-awareness is sometimes related

Table 1

Means and Standard Deviations for Subject Characteristics by Age Group

\begin{tabular}{lllllr}
\hline & \multicolumn{2}{c}{ Elderly } & & \multicolumn{2}{c}{ Young } \\
\cline { 2 - 3 } \cline { 5 - 6 } \multicolumn{1}{c}{ Characteristic } & $M$ & $S D$ & & $M$ & $S D$ \\
\hline Age in years & 73.4 & 7.4 & & 18.1 & 0.8 \\
Public consciousness of self & $20.9 *$ & 3.4 & & $26.7^{*}$ & 5.3 \\
Private consciousness of self & $28.0^{*}$ & 6.0 & $33.2^{*}$ & 7.1 \\
Social anxiety & 14.7 & 4.7 & & 17.3 & 4.7 \\
Need for cognition & 57.8 & 12.0 & 60.9 & 11.1 \\
\hline
\end{tabular}

${ }^{*} p<.05$.

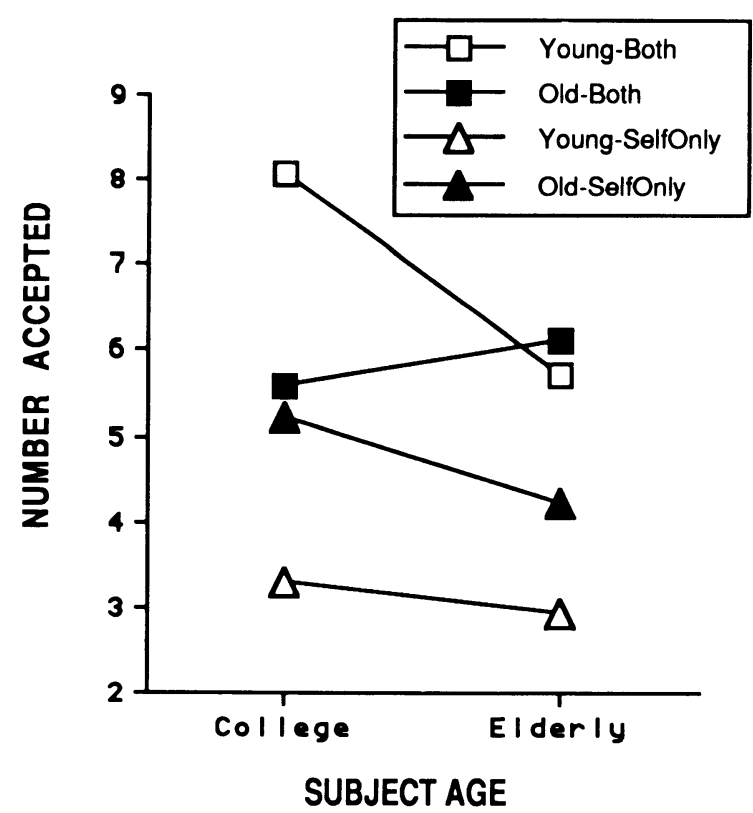

Figure 1. Number of items endorsed as descriptive of both self and other or self only, by item age and subject age, collapsed over likability.

to the magnitude of self-reference benefits (cf. Agatstein \& Buchanan, 1984), and elderly subjects are generally somewhat lower in selfawareness as measured by this scale (Mueller et al., 1986), as was also found here (see Table 1).

The final phase of the experiment was the Need for Cognition Scale (Cacioppo, Petty, \& Kao, 1984). This questionnaire assesses the extent to which an individual engages in and enjoys effortful cognitive activity. There are 18 items, such as "I really enjoy a task that involves coming up with new solutions to problems," each answered on a 5point scale. It was not known how this component changes with aging, if at all, nor whether it is related to the magnitude of self-reference benefits, so this inventory was included here for exploratory purposes. As Table 1 shows, young and elderly adults showed no difference on this scale.

\section{RESULTS}

\section{Descriptiveness Judgments}

The primary data relevant to content differences are the number of endorsements ("yes"' responses). In this case, the number of shared adjectives (i.e., those identified as descriptive of both self and other) were tabulated, followed by the number of unshared or distinctive traits (i.e., those identified as descriptive of self only), and these data were analyzed in a group (young, elderly) $\times$ item age (young, elderly) $\times$ affect (likable, unlikable) $\times$ subtype (both, self only) layout, with repeated measures on the last three factors.

At a global level, these data indicated several things. For one thing, the college students endorsed more items overall than the older adults did ( $M$ s $=44.3$ and 38.0). Furthermore, the college students endorsed about the same number of young and elderly traits ( $M s=21.6$ and 22.8), whereas the older adults endorsed more elderly traits than youthful traits $(M \mathrm{~s}=20.7$ and 17.3). 
Table 2

Correlations with Questionnaire Data, by Subject Age, Pooled over Item Age and Likability

\begin{tabular}{|c|c|c|c|c|c|c|}
\hline & \multicolumn{2}{|c|}{ Endorsements } & \multicolumn{2}{|c|}{ Latency } & \multicolumn{2}{|c|}{ Recall } \\
\hline & Both & Self Only & Both & Self Only & Both & Self Only \\
\hline \multicolumn{7}{|c|}{ College Students } \\
\hline $\begin{array}{l}\text { Social anxiety } \\
\text { Private consciousness of self } \\
\text { Public consciousness of self } \\
\text { Need for cognition }\end{array}$ & $\begin{array}{l}.04 \\
.31 \\
.43^{*} \\
-.41\end{array}$ & $\begin{array}{r}-.09 \\
.15 \\
.22 \\
.30\end{array}$ & $\begin{array}{r}.22 \\
.21 \\
-.01 \\
.13\end{array}$ & $\begin{array}{r}-.01 \\
-.12 \\
-.20 \\
.09\end{array}$ & $\begin{array}{r}-.08 \\
-.21 \\
-.01 \\
.19\end{array}$ & $\begin{array}{l}-.11 \\
-.15 \\
-.29 \\
.52 *\end{array}$ \\
\hline \multicolumn{7}{|c|}{ Elderly Adults } \\
\hline $\begin{array}{l}\text { Social anxiety } \\
\text { Private consciousness of self } \\
\text { Public consciousness of self } \\
\text { Need for cognition }\end{array}$ & $\begin{array}{r}-.30 \\
-.15 \\
-.33 \\
.04\end{array}$ & $\begin{array}{r}.31 \\
.09 \\
.30 \\
-.23\end{array}$ & $\begin{array}{r}-.23 \\
.24 \\
-.30 \\
-.16\end{array}$ & $\begin{array}{r}-.25 \\
.11 \\
-.26 \\
-.07\end{array}$ & $\begin{array}{r}-.17 \\
.07 \\
-.11 \\
.45^{*}\end{array}$ & $\begin{array}{l}.15 \\
.41 \\
.08 \\
.49^{*}\end{array}$ \\
\hline
\end{tabular}

Note $-n=20 .{ }^{*} p<.05$.

However, the result of greatest interest here was a significant triple interaction of group $\times$ item age $\times$ subtype $[F(1,39)=8.40, p<.006]$, which is plotted in Figure 1. The importance of the interaction is in two components. First, consider the two lower lines in Figure 1: The distinctive self-only items showed the same pattern for item age (namely, old items see more often as distinctive) and for subject age (namely, no significant group difference in distinctive endorsements). Second, note the top two lines in Figure 1: The items seen as less distinctive (endorsed "both") indicated no significant item-age difference for older adults, but the college students endorsed significantly more young items than old items.

Thus, these results replicate earlier findings (Mueller et al., 1986), in that age specificity was more apparent for the college students. These data also indicate that this age specificity is limited to shared traits, and does not include those that are more individualistic. Furthermore, there was a significant four-way interaction $[F(1,39)=$ $5.98, p<.02$ ], which indicated that the shared-trait results in Figure 1 (top two lines) held only for likable traits. That is, college students showed this age specificity only for desirable young traits, which they also saw as characteristic of other people.

\section{Latencies}

The decision speed for self-descriptiveness judgments indicated that there was a significant group $\times$ item age interaction $[F(1,39)=4.49, p<.05]$, since college students showed no difference for the young and old items ( $M \mathrm{~s}=1,330$ and 1,392 $\mathrm{msec}$ ), whereas the older adults were faster for the old items than for the young items (Ms $=2,468$ and $2,867 \mathrm{msec}$ ), with elderly subjects showing the usual overall deficit in response speed (cf. Kausler, 1982, and Salthouse, 1982).

There also was a significant group $\times$ subtype interaction $[F(1,39)=4.62, p<.04]$, since college students were nonsignificantly faster on the self-only items relative to the both items $(M \mathrm{~s}=1,298$ and $1,420 \mathrm{msec})$, whereas the older adults were significantly slower on the self-only items $(M s=2,819$ and $2,508 \mathrm{msec})$. Stated differently, older adults were slower than the college students on both subtypes, but more so on the self-only items.

\section{Probability of Recall}

The recall data indicated no significant effects for subject age nor item age $(F \mathrm{~s}<1)$. Furthermore, the group $X$ item age interaction also failed to reach significance $(F<1)$. The older adults tended to recall more self-only items than both items $(M \mathrm{~s}=32.1 \%$ and $21.6 \%)$, whereas the college students showed no difference $(M s=29.4 \%$ and $29.2 \%$ ), but this group $\times$ subtype interaction was only marginally significant $[F(1,39)=2.92, p<.10]$.

\section{Questionnaire Data}

The individual differences measures are shown in Table 2 . It is clear that private consciousness of self was essentially uncorrelated with any performance measure for both young and elderly adults. On the other hand, need for cognition was positively correlated with recall for both young and old adults, at least for the distinctive traits. Need for cognition was not significantly correlated with either private or public consciousness of self $[r s(40)=$ .16 and $-.14, p s>.05]$, but it was inversely correlated overall with social anxiety $[r(40)=-.40, p<.01]$, particularly for the elderly subjects $[r(20)=-.62, p<$ $.005]$.

\section{DISCUSSION}

In sum, this experiment was conducted to investigate age specificity in the self concept of young and elderly adults. Previous results had indicated that age specificity was most apparent for young adults, with elderly adults showing little preference for endorsing old trait items relative to youthful trait items. The present data replicated this general result, and indicated that the elderly show no preference for elderly items over young items for shared traits, and no significant preference for the selfonly items. The only other evidence of age specificity for the elderly adults was that elderly adults made faster decisions about the elderly items, regardless of whether the items were judged both or self-only in terms of distinctiveness.

The young adults in the present study again showed a preference for the young items over the elderly traits, but this was more apparent for the shared traits ("both") than for the more distinctive self-only traits, and more so for likable than for unlikable items. This may indicate 
similarity of the self-image to the image of other people for young adults, whereas the elderly have a self-image that is more differentiated from their images of other people.

\section{REFERENCES}

Agatstein, F. C., \& Buchanan, D. B. (1984). Public and private selfconsciousness and the recall of self-relevant information. Personality \& Social Psychology Bulletin, 10, 314-325.

BREWER, M. B., \& LUI, L. (1984). Categorization of the elderly by the elderly: Effects of perceiver's category membership. Personality \& Social Psychology Bulletin, 10, 585-595.

Buss, A. H. (1980). Self consciousness and social anxiety. San Francisco: W. H. Freeman.

Cacioppo, J. T., Petty, R. E., \& KaO, C. F. (1984). The efficient assessment of need for cognition. Journal of Personality Assessment, 48, 306-307.

DERRY, P. A., \& KUIPER, N. A. (1981). Schematic processing and selfreference in clinical depression. Journal of Abnormal Psychology, 90, 286-297.

Greenwald, A. G., \& Pratkanis, A. R. (1984). The self. In R. S. Wyer \& T. K. Srull (Eds.), Handbook of social cognition (Vol. 3, pp. 129-178). Hillsdale, NJ: Erlbaum.
Heckhausen, J., Dixon, R. A., \& Baltes, P. B. (1989). Gains and losses in development throughout adulthood as perceived by different adult age groups. Developmental Psychology, 25, 109-121.

KAUSLER, D. H. (1982). Experimental psychology and human aging. New York: Wiley.

MARKUS, H. (1983). Self knowledge: An expanded view. Journal of Personality, 51, 543-565.

MUeller, J. H., \& Ross, M. J. (1984). Uniqueness of the self-concept across the life span. Bulletin of the Psychonomic Society, 22, 83-86.

Mueller, J. H., Ross, M. J., \& Heesacker, M. (1984). Distinguishing me from thee. Bulletin of the Psychonomic Society, 22, 79-82.

Mueller, J. H., Wonderlich, S., \& DUGAN, K. (1986). Self-referent processing of age-specific material. Psychology \& Aging, 1, 293-299.

ROGERS, T. B., KUIPER, N. A., \& KIRKER, W. S. (1977). Self-reference and the encoding of personal information. Journal of Personality \& Social Psychology, 35, 677-688.

Salthouse, T. A. (1982). Adult cognition: An experimental psychology of human aging. New York: Springer-Verlag.

(Manuscript received August 10, 1989.) 